\title{
Aspartic di-dodecyl ester hydrochloride acid and its ZnO-NPs derivative, as ingenious green corrosion defiance for carbon steel through theoretical and experimental access
}

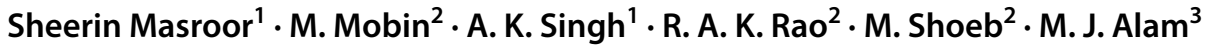

Received: 5 August 2019 / Accepted: 17 October 2019 / Published online: 2 January 2020

(c) Springer Nature Switzerland AG 2020

\begin{abstract}
The ecological friendly and readily biodegradable amino acid based surfactant, aspartic di-dodecyl ester hydrochloride acid (ADH) and its $\mathrm{ZnO}-\mathrm{NPs}$ derivative was synthesized and tested as corrosion inhibitor for metal in acidic medium. The synthesized surfactant was characterized by experimental and theoretical Fourier-transform infrared spectroscopy. The synthesis of ZnO-NPs with surfactant was confirmed by TEM/EDAX. The corrosion inhibition studies were performed using gravimetric analysis, potentiodynamic polarization and theoretical chemical calculations. The highest inhibition efficiency (\%IE) was found to be $87.62 \%$ at $303.15 \mathrm{~K}$ with concentration $1000 \mathrm{ppm}$ of $\mathrm{ADH}$ alone, while which raises to $92.59 \%$ with $\mathrm{ADH}-\mathrm{ZnO}$ and was in close agreement as found by potentiodynamic results. Out of many adsorption isotherms, Langmuir was best fitted. The surface morphology were done by scanning electron microscopy (SEM) and energy dispersive X-ray spectroscopy (EDAX). Potentiodynamic polarization study confirms the type of inhibitor. Also the results of gravimetric analysis are in good agreement with that of potentiodynamic measurements. Inhibition mechanism was also investigated by calculating the thermodynamic and activation parameters like $\Delta \mathrm{G}^{\circ}, \mathrm{E}_{\mathrm{a}}, \Delta \mathrm{H}$ and $\Delta \mathrm{S}$. SEM pictographs show a different morphology in presence of $\mathrm{ADH}$ and showed the existence of an adsorbed protective film on the metal surface.
\end{abstract}

Keywords Amino acid · Aspartic di-dodecyl ester hydrochloride acid · Surfactant · FTIR · DFT

\section{Introduction}

The use of biodegradable/ecofriendly surfactants is very vast as it can be harvested in number of fields as said by Bognolo. Its use over conventional is due to many factors, like complex structure, higher biodegradability and low toxicity, high surface activity, greater ability to form molecular assemblage and liquid crystal at very minimal concentration, antimicrobial and antitumor activity, the distortion of structure is stable at extreme conditions of $\mathrm{pH}$, salinity and temperature [1]. The use of various green surfactants is most prominent in bioremediation, industrial, food processing, pharmaceutical applications and corrosion inhibition.

The corrosion issue of low carbon steel in acidic mediums has been a subject of both academic and industrial involvement and has received ample attention during the last few decades. Among the diverse acids used, hydrochloric acid is widely used for eradication of rust and scales in multiple industrial operations. However, hydrochloric acid is a strong corrosive agent and its corrosivity needs to be guarded by using appropriate corrosion inhibitor.

\section{Electronic supplementary material The online version of this article (https://doi.org/10.1007/s42452-019-1515-z) contains} supplementary material, which is available to authorized users.

Sheerin Masroor, masroor.sheerin@gmail.com | 'Department of Chemistry, A.N. College, Patliputra University, Patna, Bihar 800013, India. ${ }^{2}$ Department of Applied Chemistry, ZHCET AMU, Aligarh Muslim University, Aligarh, UP 202002, India. ${ }^{3}$ Department of Physics, Faculty of Science, Aligarh Muslim University, Aligarh, UP 202002, India. 
Surfactants, because of their remarkable ability to influence the properties of surfaces and interfaces, have been effectively oppressed as corrosion obstructer in aggressive medium [2-5]. The adsorption phenomenon depends upon the structure and concentration of surfactant molecules used in the contacting medium, as surfactants possessing one hydrophilic and other hydrophobic unit; both comparatively responsible for favoring the adsorption process at metallic surfaces. The adsorbed surfactant molecules form a monolayer or bilayer, hemi micelles or ad micelles and prevent the acids to attack the superficial surface, and thus diminish the corrosion.

The use of various inhibitors have been examined and the relationship between the structure of the inhibitor molecule and their efficiencies [6-10]. Before very less attention has been inclined towards dependence of the corrosion inhibition efficiency on the size of the used inhibitor molecule in addition with the electronic distribution over the inhibitor molecule. With the rise in advancement of nanotechnology, the corrosion inhibiting thin films of inhibitors measured in the micron and nanometeric scales are increasing to many folds in many scientific and technological applications [11]. The high tendency to interact with each other to form agglomeration due to the higher surface area of the nanosized particles in comparison to the micro sized caused by their large surface area to volume ratio $[12,13]$.

The $\mathrm{ZnO}-\mathrm{NPs}$ are experimented as nontoxic and biocompatible in many applications [14]. The physical and chemical stability, of the nanoparticles made from $\mathrm{ZnO}$ with surfactants were proved via wide range of potential applications in many research field and also in chemical industries [15].

There are excess of literature showing enhancing corrosion inhibition efficiency using various nanoparticles such as; $\mathrm{Cu}_{2} \mathrm{O}, \mathrm{ZnO}, \mathrm{TiO}_{2}, \mathrm{ZrO}_{2}$ nanoparticles, and Au nanoparticles [16-20].

Amino acid based surfactants are gaining much interest in the field of inhibition of corrosion research, mainly because of their nontoxic, biodegradable, relatively cheap, and completely soluble character.

\section{Experimental procedure}

\subsection{Metallic sample preparation}

Carbon steel segment with low carbon content with composition $0.034 \%$ C, $0.176 \% \mathrm{Mn}, 0.0103 \% \mathrm{P}, 0.059 \% \mathrm{~Pb}$, $0.014 \% \mathrm{Al}, 0.034 \% \mathrm{~V}$ and remaining contains Fe were used for corrosion inhibition studies. Steel sample's having size: $2.0 \times 2.0 \times 0.04 \mathrm{~cm}$ were fabricated with number of emery papers with different grades such as 300,600 and 1200 followed by flushing in acetone and double distilled water (DDW) and then dried in air. Previous to the experiment, the substrates were treated as described and freshly used with no future storage. The aggressive solution of $1 \mathrm{M} \mathrm{HCl}$ was prepared by using AR grade $\mathrm{HCl}$ (Qualigens) and DDW.

\subsection{Synthesis and characterization of amino based surfactant}

\subsubsection{Synthesis of amino based surfactant (ADH)}

The green synthesis of amino based surfactant (ADH) studied was fixed in laboratory following two steps, first by reacting L-aspartic acid and $\mathrm{p}$-Toluene sulfuric acid in Toluene which was refluxed for $1 \mathrm{~h}$ maintaining at temperature $383.15 \mathrm{~K}$. Succeeding first step, addition of Dodecanol, (which is a kind of fatty alcohol) to the solution, followed by stirring for $12 \mathrm{~h}$ under reflux. The reaction mixture was retrieve after secondary step was then evaporated and dissolved in ethyl acetate. Meanwhile, ethyl acetate solution was washed using $10 \%$ sodium carbonate solution and distilled water, twice. To precipitate the product, $12 \mathrm{M} \mathrm{HCl}$ solution was further added. White powder was obtained after drying it in vacuum [21]. The synthesized product was characterized by FTIR. The chemical structure is given in Fig. 1.

\subsubsection{Synthesis of surfactants nano particle}

We synthesized ZnO-NPs through anegg protein-templated sol-gel method according to our previous work with slight modification $[22,23]$ According to this method, briefly freshly extracted egg albumen $(10 \mathrm{mg} / \mathrm{mL})$ were prepared in milli-Q water and mixed drop wise into $50 \mathrm{~mL}$ of aqueous $0.01 \mathrm{M}$ zinc acetate dihydrated solution. The mixture was stirred for $6 \mathrm{~h}$ at room temperature to form the colloidal solution. The colloidal solution was precipitated by the addition of ammonia $\left(\mathrm{NH}_{3}\right)$ at $\sim \mathrm{pH} 8.0$ and centrifuged at 10,000 rpm for $5 \mathrm{~min}$ and thrice washed with the MQ water. The washed material was collected and dried in the vacuum oven and grounded into a fine powder. The obtained dried powder was subjected to sintering

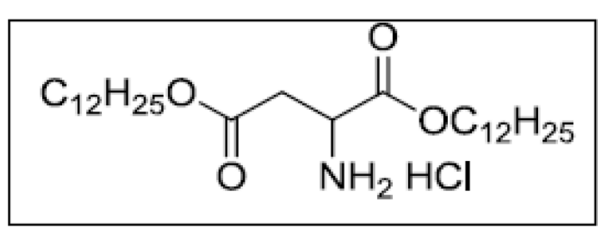

Fig. 1 Chemical structure of aspartic di-dodecyl ester hydrochloride acid 
at $573.15 \mathrm{~K}$ for $4 \mathrm{~h}$ and synthesized $\mathrm{ZnO}$-NPs were stored in a dry and dark place until further use.

For modification, the ZnO-NPs was dispersed in $100 \mathrm{~mL}$ of ethanol and heated to $80^{\circ} \mathrm{C}$ under reflux. Subsequently, the previously synthesized surfactant ADH $(5 \mathrm{mg} / \mathrm{mL}$ in ethanol) was added to the reaction mixture, which was maintained at $308.15 \mathrm{~K}$ for $1 \mathrm{~h}$. The reaction mixture was then cooled under magnetic stirring and centrifuged (10 min, $5000 \mathrm{rpm})$. The solvent was decanted off, and the solid was washed twice with ethanol (which involved dispersion, centrifugation, and decantation).

\subsection{Gravimetric analysis}

The gravimetric analysis were carried out in a thermo stated water bath for duration of $6 \mathrm{~h}$ as per ASTM designation G1-90. The metal specimens were freshly prepared, which were suspended in $250 \mathrm{ml}$ beakers containing $200 \mathrm{ml}$ of test solutions maintained at $303.15 \mathrm{~K}$ and $333.15 \mathrm{~K}$ for the surfactant alone and at $303.15 \mathrm{~K}$ for the $\mathrm{ZnO}-\mathrm{ADH}$. The coupon samples were immersed in triplicate and average corrosion rate was calculated. The corrosion rate in mpy was calculated using equation [24].

Corrosion rate $(\mathrm{CR})(\mathrm{mpy})=\frac{534 \mathrm{~W}}{\rho \mathrm{AT}}$

where $\mathrm{W}$ is weight loss in $\mathrm{mg} ;$ " $\rho$ " is the density of carbon steel in $\mathrm{g} / \mathrm{cm}^{3}$; " $A$ " is the area of specimen in centimeter squares and " $\mathrm{t}$ " is exposure time in hrs. The percentage corrosion inhibition efficiency $(\eta)$ of the $A D H$ and $A D H-Z n O$ was evaluated using the following equation:

$(\eta)=\frac{\mathrm{CR}_{\mathrm{o}}-\mathrm{CR}_{\mathrm{i}}}{\mathrm{CR}_{\mathrm{o}}} \times 100$

where $C R_{0}$ is the corrosion rate of carbon steel in bare $1 \mathrm{M} \mathrm{HCl}$ solution or absence of $\mathrm{ADH} / \mathrm{ADH}-\mathrm{ZnO}$ and $C \mathrm{R}_{\mathrm{i}}$ is the corrosion rate of carbon steel in presence of $A D H$ and ADH-ZnO nanoparticle composite.

\subsection{Potentiodynamic polarization analysis}

The potentiodynamic polarization analysis were drifted out using a conventional three-electrode cell set-up, consisting of low carbon steel working electrode (WE), a platinum counter electrode (CE) and a saturated calomel electrode $(\mathrm{SCE}) / \mathrm{Ag} / \mathrm{AgCl}$ electrode (saturated $\mathrm{KCl}$ ) as reference electrode with inbuilt impedance electrochemical workstation, Autolab Potentiostat/Galvanostat, model $128 \mathrm{~N}$. The cell set-up includes, most important Luggin-Haber capillary in the assembly, keeping its tip very close to the surface of the working electrode, which is essential to minimize IR drop.
The experimental data were obtained by overdrawn the potential limits -0.25 to $0.25 \mathrm{~V}$ from open circuit potential at a scan rate of $0.0005 \mathrm{~V} / \mathrm{s}$. The low carbon steel was permitted to stabilize in the $1 \mathrm{M} \mathrm{HCl}$ for approx $30 \mathrm{~min}$ prior to the experiments performed. All the experiments were done at room temperature $(303.15 \pm 1 \mathrm{~K})$.

The percentage inhibition efficiency $(\eta)$ was calculated from the measured $\mathbf{i}_{\text {corr }}$ values using the relationship:

$\eta=\left(1-\frac{i_{\text {corr }}}{i_{\text {corr }}^{o}}\right) \times 100$

where $\mathbf{i}_{\text {corr }}$ is the current density of metal in added surfactant solution and its nanoparticle counterpart and $i_{\text {corr }}^{\circ}$ is current density of metal in $1 \mathrm{M} \mathrm{HCl}$ alone.

\subsection{Computational details}

Density functional theory (DFT) approach plays an important role in portraying the molecules as well as to obtain their various meaning full properties like reactivity indices, Fukui functions, dipole moment, atomic charges, molecular volume, electrostatic potential, frontier molecular orbitals etc. DFT calculations are widely used to review the inhibition performance of molecule and its adsorption mechanism with metal surface. In the present study, the ground state optimized structure, IR frequencies and various relevant molecular parameters of the compound made from aspartic acid were obtained using hybrid functional B3LYP along with triple zeta basis set $6-311 \mathrm{G}(\mathrm{d}, \mathrm{p})$ as implemented in Gaussian 09 software $[25,26]$.The DFT/B3LYP analysis has been chosen for the present calculations due to high accuracy and low computational. The molecular geometry of the present compound was fully optimized in the ground electronic state under tight convergence criterion and then IR frequencies were obtained. The positive values of frequency correlate that the optimized geometry corresponds to minima on the potential energy surface. The necessary molecular parameters of aspartic acid compound were obtained by geometry optimization and frequency calculations at same level of theory. The crucial parameter, such as energy gap between highest occupied molecular orbital (HOMO) and lowest unoccupied molecular orbital (LUMO) was estimated using both DFT and TD-DFT calculations. The frontier molecular orbitals (HOMO and LUMO) and molecular electrostatic potential (MEP) surfaces have been obtained using Gauss View 5 program [27].

\subsection{Scanning electron microscopy (SEM) and energy dispersive X-ray spectroscopy (EDX) studies}

The superficial morphology of the carbon steel specimens dipped in $1 \mathrm{M} \mathrm{HCl}$ alone and with $\mathrm{ADH} / \mathrm{ADH}-\mathrm{ZnO}$ was evaluated using SEM (Model: JEOL JSM-6510LV), and EDX. 


\subsection{Transmission electron spectroscopy}

The morphology study of the synthesized surfactant with nanoparticle was done by High-resolution transmission electron microscopy with EDAX.

\section{Results and discussion}

\subsection{Characterization of amino derived surfactant}

The characterization was done by Fourier transform infrared spectroscopy (FTIR). The concerned compound consists $-\mathrm{NH}_{2}, \mathrm{O}-\mathrm{C}=\mathrm{O}$, and $\mathrm{Cl}-\mathrm{H}$ groups along with carbon chain $\left(\mathrm{CH}_{2}, \mathrm{CH}_{3}, \mathrm{C}-\mathrm{H}\right)$ to the either sides of these functional groups.

The comparison of simulated and experimental IR spectra along with some important band assignments is presented in Fig. 2.

The experimental and simulated IR spectra have been found in good accord. Some important fundamental bands appeared in the FTIR have been assigned using theoretical harmonic frequencies and animated modes, Table 1. The theoretical IR frequencies are found larger than that of experimental one due to fact that the calculations have been performed in the harmonic approximation for isolated gaseous phase molecule while experimental FTIR belongs to solid phase. Some important IR bands appeared in the present FTIR spectrum are discussed.

The characteristic IR bands with weak to medium intensity due to $\mathrm{NH}_{2}$ stretching vibrations normally appear in the region $3550-3250 \mathrm{~cm}^{-1}[28,29]$. A broad band appeared at $3434 \mathrm{~cm}^{-1}$ in the FTIR spectrum is assigned to asymmetric stretching vibrations (Table 1). The theoretical IR frequencies of asymmetric and symmetric $\mathrm{NH}_{2}$ stretching vibrations are found to be 3587 and $3502 \mathrm{~cm}^{-1}$ respectively. The $-\mathrm{NH}_{2}$ scissoring vibration occurs in the region $1650-1550 \mathrm{~cm}^{-1}$ [30]. A medium intensity band appeared at $1603 \mathrm{~cm}^{-1}$ in the FTIR spectrum is assigned to $-\mathrm{NH}_{2}$ scissoring vibration. The rest vibrations of $\mathrm{NH}_{2}$ group appeared with mixing of others at lower wave number region.

The $\mathrm{C}-\mathrm{H}$ stretching vibrations in $\mathrm{CH}, \mathrm{CH}_{2}$ and $\mathrm{CH}_{3}$ groups normally occur in the region $3000-2850 \mathrm{~cm}^{-1}$ [30]. In the present spectrum the $\mathrm{C}-\mathrm{H}$ stretching vibrations are observed within said region (Table 1 ). The $\mathrm{C}-\mathrm{H}$ deformation vibrations have been observed with mixing of others below the $1550 \mathrm{~cm}^{-1}$ in the present FTIR.
Fig. 2 Experimental and simulated IR spectra for aspartic di-dodecyl ester hydrochloride acid
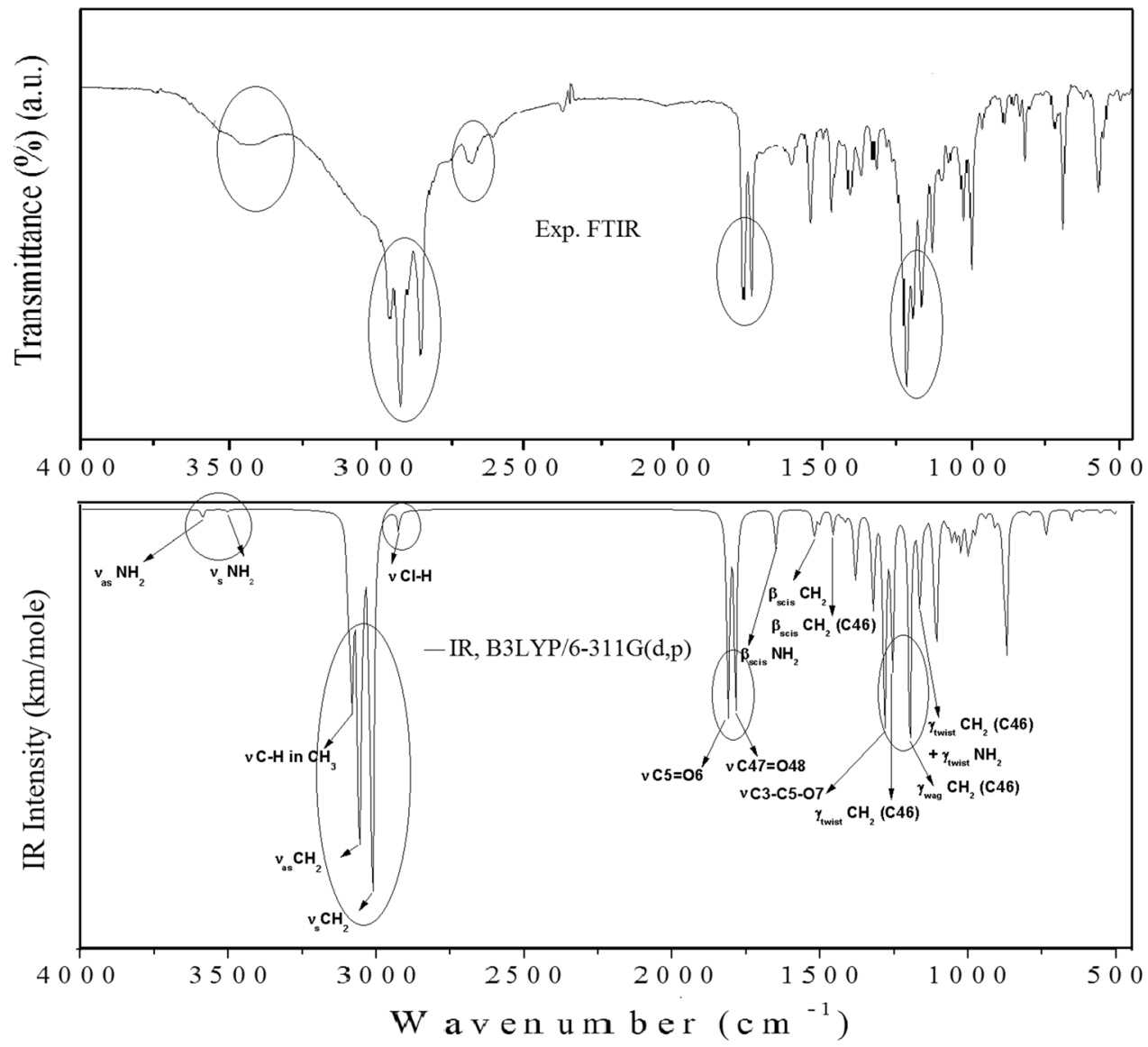
Table 1 Some important fundamental IR bands assignments for aspartic di-dodecyl ester hydrochloride acid

\begin{tabular}{|c|c|c|}
\hline $\begin{array}{l}\text { Experimental IR } \\
\left(\mathrm{cm}^{-1}\right)\end{array}$ & $\begin{array}{l}\text { Theoretical IR } \\
\left(\mathrm{cm}^{-1}\right)\end{array}$ & Assignments \\
\hline \multirow[t]{2}{*}{$3434 \mathrm{br}$} & 3587 & $v_{\text {as }} \mathrm{NH}_{2}$ \\
\hline & 3502 & $v_{\mathrm{s}} \mathrm{NH}_{2}$ \\
\hline $2957 s$ & 3063 & $v \mathrm{C}-\mathrm{H}$ in $\mathrm{CH}_{3}$ \\
\hline 2920vs & 3061 & $v_{\mathrm{as}} \mathrm{CH}_{2}$ \\
\hline $2851 \mathrm{vs}$ & 3056 & $v_{5} \mathrm{CH}_{2}$ \\
\hline $2682 w$ & 2924 & $v \mathrm{Cl}-\mathrm{H}$ \\
\hline $1767 v s$ & 1811 & $v \mathrm{C} 5=\mathrm{O} 8$ \\
\hline 1738vs & 1786 & $v C 47=048$ \\
\hline $1603 m$ & 1650 & $\beta_{\text {sciss }} \mathrm{NH}_{2}$ \\
\hline $1544 s$ & 1518 & $\beta_{\text {sciss }} \mathrm{CH}_{2}$ \\
\hline $1468 s$ & 1456 & $\beta_{\text {sciss }} \mathrm{CH}_{2}(\mathrm{C} 46)$ \\
\hline $1409 s$ & 1418 & $\beta \mathrm{C} 3-\mathrm{H} 4$ \\
\hline $1369 m$ & 1382 & $\gamma_{\text {wag }} \mathrm{CH}_{2}+\beta \mathrm{C} 3-\mathrm{H} 4$ \\
\hline $1323 m$ & 1320 & $\gamma_{\text {wag }} \mathrm{CH}_{2}+\beta \mathrm{C} 3-\mathrm{H} 4+\beta \mathrm{N}-\mathrm{H}$ \\
\hline $1220 v s$ & 1282 & $v \mathrm{C} 3-\mathrm{C} 5-\mathrm{O} 7+\beta \mathrm{C} 3-\mathrm{H} 4+\beta \mathrm{N}-\mathrm{H}$ \\
\hline $1195 s$ & 1255 & $v \mathrm{C} 3-\mathrm{C} 5+\gamma_{\text {twist }} \mathrm{CH}_{2}(\mathrm{C} 46)$ \\
\hline $1166 \mathrm{~s}$ & 1197 & $\begin{array}{l}\beta_{\text {sciss }} \mathrm{CH}_{2}(\mathrm{C} 46)+v \mathrm{C} 52-\mathrm{O} 49- \\
\quad \mathrm{C} 47+\beta \mathrm{C} 3-\mathrm{H} 4\end{array}$ \\
\hline $1127 \mathrm{~s}$ & 1163 & $\gamma_{\text {twist }} \mathrm{CH}_{2}(\mathrm{C} 46)+\beta \mathrm{N}-\mathrm{H}$ \\
\hline 1096w & 1107 & $v \mathrm{~N} 1-\mathrm{C} 3-\mathrm{C} 46$ \\
\hline $1026 s$ & 1025 & $v C 8-07+v C-C$ \\
\hline $1002 s$ & 1002 & $v \mathrm{C} 8-\mathrm{O} 7$ \\
\hline
\end{tabular}

$s$ strong, $v s$ very strong, $m$ medium strong, $b r$ broad, $w$ weak, $v$ stretching, $v_{a s}$ asymmetric stretching, $v_{s}$ symmetric stretching, $\beta$ in plane bending, $\gamma$ out of plane bending, $\beta_{\text {sciss }}$ scissoring, $\gamma_{\text {wag }}$ wagging, $\gamma_{\text {twist }}$ twisting vibrations

A very strong vibration due to $\mathrm{C}=\mathrm{O}$ stretching occur in the region $1850-1550 \mathrm{~cm}^{-1}[31,32]$. In the present FTIR, this vibration is assigned at 1767 and $1738 \mathrm{~cm}^{-1}$.

The IRbands due to $\mathrm{C}-\mathrm{C}$ stretching vibrations (skeletal vibration) occur in the region $1260-700 \mathrm{~cm}^{-1}$ [29]. The weak bands due to this vibration are appeared in the present FTIR spectrum within the said region.

A weak band appeared at $2682 \mathrm{~cm}^{-1}$ in the present FTIR is assigned to $\mathrm{H}-\mathrm{Cl}$ stretching vibration. The corresponding theoretical value is predicted at $2924 \mathrm{~cm}^{-1}$. The large deviation is observed due to large anharmonicity associated to this vibration as well as intermolecular interactions which have not been taken into account in theory.

\subsubsection{Characterization of amino derived surfactant with $\mathrm{ZnO}$}

For the interaction of ZnO-NPs and surface interaction, we investigated through the FTIR spectroscopy. A comparison of the sample (a) ZnO-surfacatant (b) surfactant in (Figure $\mathrm{S} 2$ ) spectra reveal some strict differences. The $\mathrm{N}-\mathrm{H}$ primary amine band present at $3400 \mathrm{~cm}^{-1}$ in the both samples at the same position but $\mathrm{N}-\mathrm{H}$ stretching band at $1560 \mathrm{~cm}^{-1}$ is absent after interaction of ZnO NPs with the surfactant and confirm the interaction through the amide bond [33]. The furthermore band at $815 \mathrm{~cm}^{-1}$ is shown primary amide $(\mathrm{N}-\mathrm{H}$, bending out of plane) is absent after interaction of ZnO NPs. After interaction of ZnO NPs with surfactant, surfactant structure retains their properties confirm through the bands at $2900 \mathrm{~cm}^{-1}, 1430 \mathrm{~cm}^{-1}, 1370 \mathrm{~cm}^{-1}$ and $720 \mathrm{~cm}^{-1}$ for $\mathrm{C}-\mathrm{H} \mathrm{sp}{ }^{3}$ stretching, $\mathrm{CH}_{2}$ methylene group, $\mathrm{CH}_{3}$ methyl group, and $\mathrm{CH}_{2}$ long chain bending respectively $[34,35]$. And furthermore, $1215 \mathrm{~cm}^{-1}$ has confirmed the presence of ester (-COO-) in the structure in the both samples. So we can conclude the successful interaction of ZnO NPs through the surfactant.

\subsection{Gravimetric measurements}

The corrosion inhibition of carbon steel in $1 \mathrm{M} \mathrm{HCl}$ at 303.15 and $333.15 \mathrm{~K}$ in absence and presence of different concentrations of $\mathrm{ADH}$ and $\mathrm{ADH}-\mathrm{ZnO}$ at $303.15 \mathrm{~K}$ alone was studied using gravimetric measurement technique and the data obtained after $6 \mathrm{~h}$ of immersion have been recorded in Table $2 \mathrm{~A}$ and $\mathrm{B}$. Both the results were compared and $\mathrm{ADH}-\mathrm{ZnO}$ was higher corrosion efficiency than pristine surfactant $A D H$, it might be due to its high surface area of nanocomposite. The corrosion rate is diminished in presence of $\mathrm{ADH}$ in free acid solution when seen at temperature $303.15 \mathrm{~K}$. More corrosion rate diminishing was seen when ADH-ZnO was used. Also the corrosion rate increased at elevated temperature at all concentrations studied for ADH alone. The discrepancy of \% IE as a function of ADH concentrations at $303.15 \mathrm{~K}$ and $333.15 \mathrm{~K}$ reveals that at given temperature the IE increases with increase in surfactant concentrations. The increased IE with increasing $A D H$ concentrations indicates that more $\mathrm{ADH}$ molecules are adsorbed on the steel surface at higher concentration, leading to greater surface coverage which leads to formation of a protective film. The effect of temperature on IE is quite pronounced; the IE decreases when temperature is hiked to 333.15 from $303.15 \mathrm{~K}$. A decrease in IE with increase in temperature at all the concentrations suggests the surfactant is adsorbed by weak Vander Waal's forces. This may be due to the fact that higher temperature may distort the structure of ADH leading to bad coverage over the steel surface.

\subsection{Adsorption mechanism}

High percentage inhibition efficiency $(\eta)$ obtained at $303.15 \mathrm{~K}$, is due to the strong adsorption of amino ester based surfactant, which in turn may be due to presence of di-alkyl group linked at two ends of green surfactant, 
Table 2 Corrosion rate, inhibition efficiency and degree of surface coverage for carbon steel in $1 \mathrm{M} \mathrm{HCl}$ in absenteeism and presence of the (A) $\mathrm{ADH},(\mathrm{B}) \mathrm{ADH}-\mathrm{ZnO}$

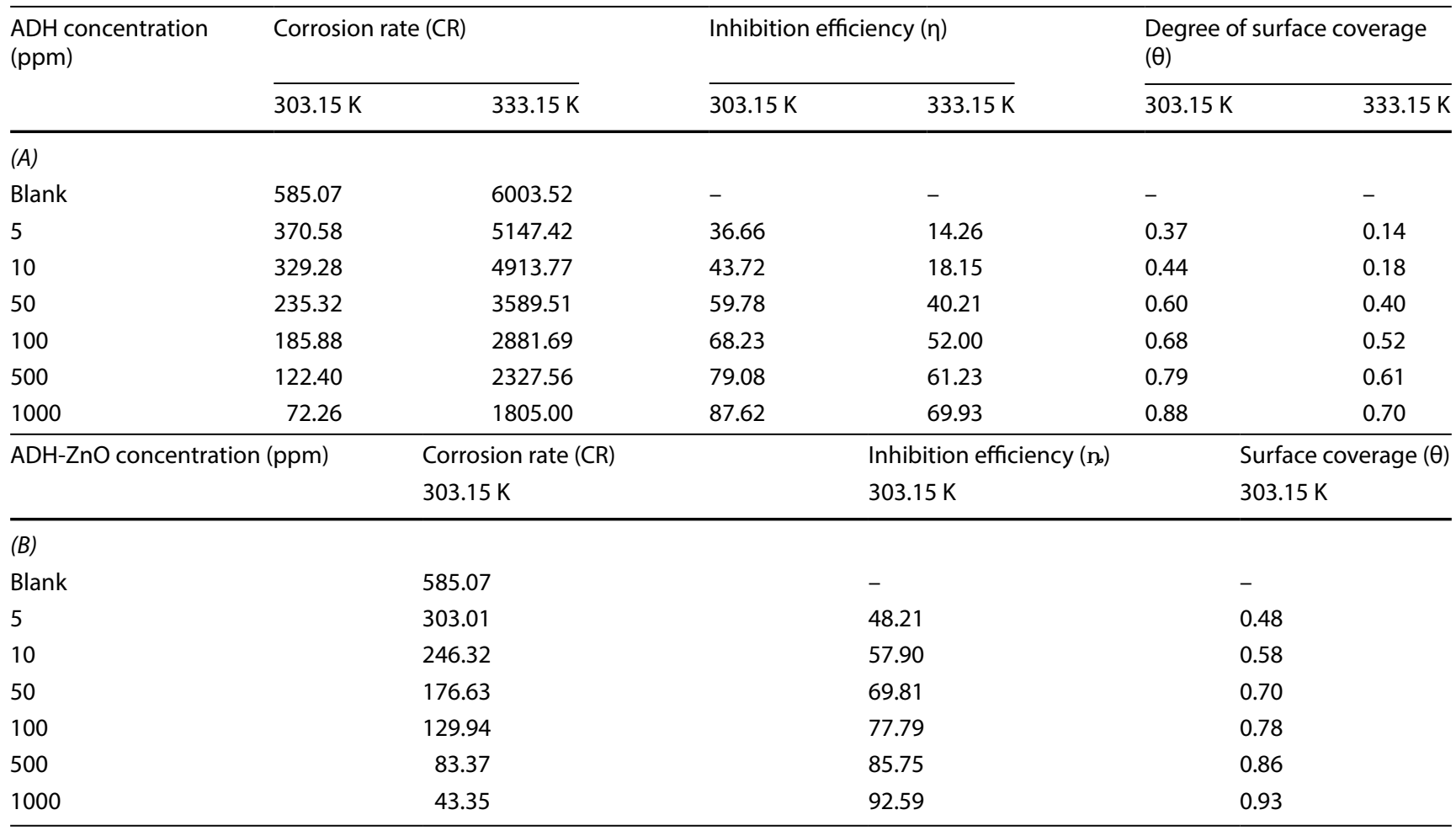

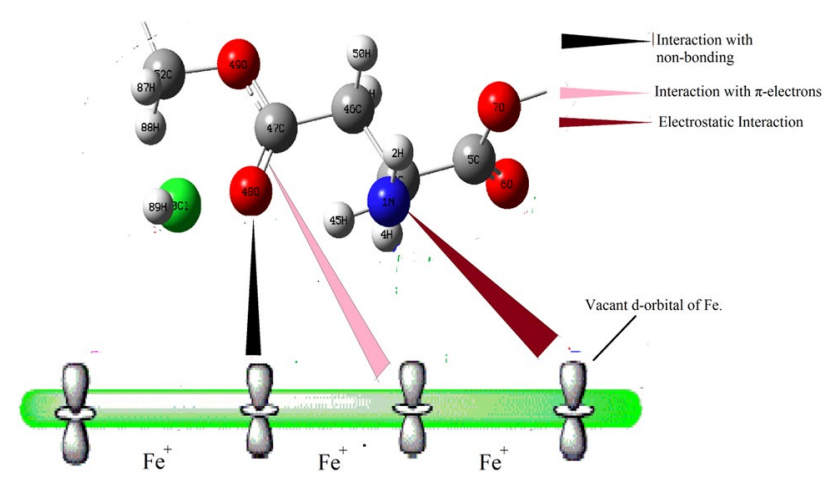

Fig. 3 The interaction sites present on aspartic di-dodecyl ester hydrochloride acid interacting with carbon steel surface

showing better adsorption coverage over the low carbon steel surface. In addition, it also has two functional groups, which are an amine group and a carboxyl group. The used amino based surfactant contains a chain of 12 carbon at both ends, in the middle of the molecule presence of oxygen, nitrogen and chlorine enhancing the charge density and favoring better adsorption over the surface. Considering the effect of temperature change on inhibition behavior of $A D H$, the inhibition efficiency also decreases at elevated temperature. This specified the capability of green surfactants to inhibit corrosion of low carbon steel at low temperature compared to its use at higher temperatures, which may be due to its structure degradation at high temperature. Elevation in temperature causes long chains of surfactant may break into many fragments, leading to less adsorption coverage over the surface, which leads lesser inhibition. The most active site of the surfactant is present in between, where the electron density is highest (Fig. 3). The vacant $\mathrm{d}$-orbital of iron $(\mathrm{Fe})$ present in carbon steel, coordinated differently with (1) unpaired or non-bonding electron of oxygen, (2) $\pi$-electrons present in bond between oxygen and carbon, (3) electrostatically with positive charged nitrogen. The green surfactant, ADH adsorb on steel surface by physical adsorption to the low carbon steel which is more favored at low temperature due to lesser kinetic energy barrier.

\subsection{Adsorption isotherm}

Adsorption isotherms are very significant as they regulate the mechanism of adsorption of adsorbate in organo-electrochemical reactions. Some of the studied adsorption isotherms are Freundlich, Brunauer-Emmett-Teller (BET) and Langmuir, which was found to be suitable for the experimental findings here at both temperature studied. The isotherm which best fit was Langmuir and is described by equation: [36] 


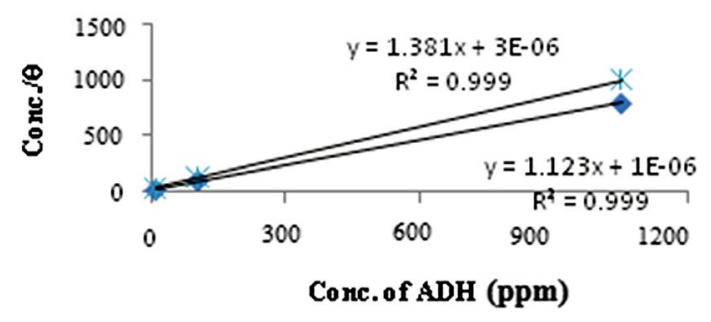

Fig. 4 Langmuir adsorption isotherm of surfactant at (1) $30^{\circ} \mathrm{C}(2)$ $60^{\circ} \mathrm{C}$

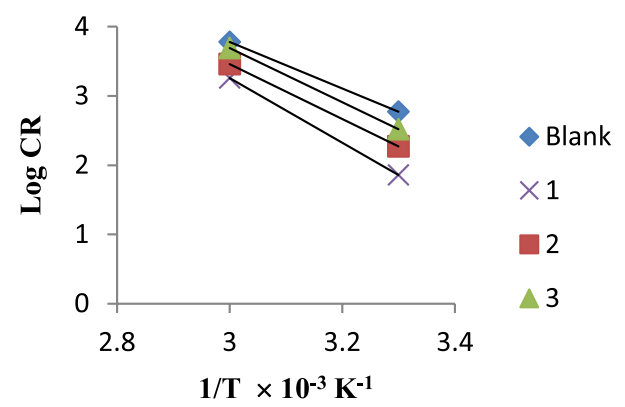

Fig. 5 Log $C R$ versus $1 / T$ plots in absence and presence of $A D H$ $(1=1000 \mathrm{ppm}, 2=100 \mathrm{ppm}, 3=10 \mathrm{ppm})$

$\frac{C}{\theta}=\frac{1}{k}+C$

where $\theta$ is the degree of surface coverage or the number of sites of the surface which are covered with surfactant molecule, $\mathrm{k}$ is the equilibrium constant for distribution of adsorbate between the surface and the solution and $C$ is the $\mathrm{ADH}$ concentration. The given equation number 4 , rearranges as $\theta=C \times k / 1+C \times k$. As this equation minimizes to, $\theta=C \times k$, when the concentration is low. The plots of $\mathrm{C} / \theta$ versus $C$ for low carbon steel corrosion in $1 \mathrm{M} \mathrm{HCl}$ for ADH surfactants at $303.15 \mathrm{~K}$ and $333.15 \mathrm{~K}$ is shown in Fig. 4. Adsorption parameters such as slope and regression value are interpreted from the Langmuir adsorption isotherm. The high values of $\mathrm{K}$ indicate that the ADH was strongly adsorbed on the steel surface.

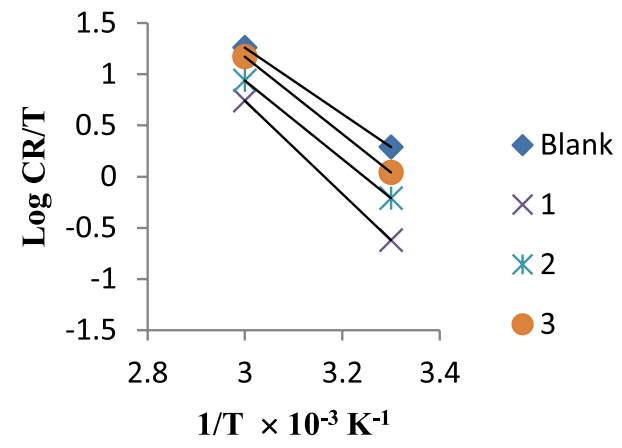

Fig. 6 Log CR/T versus $1 / T$ plots in the absence and presence of $\mathrm{ADH}(1=1000 \mathrm{ppm}, 2=100 \mathrm{ppm}, 3=10 \mathrm{ppm})$

\subsection{Kinetic and thermodynamic parameters}

In order to elucidate the inhibitive properties of the ADH and the temperature dependence on the corrosion rates, the apparent activation energy $\left(E_{a}\right)$ for the corrosion process in the absence and presence of ADH were evaluated from Arrhenius equation given by relationship: [37]

$\log C R=\log A-\frac{E_{a}}{2.303 R T}$

where $C R$ is the corrosion rate of the green synthesized surfactant, $A$ is Arrhenius constant, $R$ is the molar gas constant and $T$ is the absolute temperature. The logarithm of corrosion rate ( $\log C R$ ) versus reciprocal of absolute temperature $(1 / \mathrm{T})$ plot for $1 \mathrm{M} \mathrm{HCl}$ alone and with additive $(A D H)$ is presented in Fig. 5. The values of activation energy obtained from the slope of the linear plot are presented in Table 3. The supplementary kinetic parameters like enthalpy of adsorption $(\Delta \mathrm{H})$ and entropy of adsorption $(\Delta S)$ for the corrosion of low carbon steel in $1 \mathrm{M} \mathrm{HCl}$ in presence of ADH was obtained by the equation: [37]

$C R=\frac{R T}{N h} \exp \left(\frac{\Delta S}{R}\right) \exp \left(\frac{\Delta H}{R T}\right)$

where " $\mathrm{N}$ " is the Avogadro's number, " $\mathrm{h}$ " is the Planck's constant, " $R$ " is the molar gas constant and " $T$ " is the absolute temperature. Figure 6 represents the plots of log (CR/T) versus $1 / \mathrm{T}$ for $1 \mathrm{M} \mathrm{HCl}$ and $\mathrm{ADH}$ additive [37] Linear plot was
Table 3 Calculated values of kinetic/thermodynamic parameters of $A D H$

\begin{tabular}{llllll}
\hline $\mathrm{ADH}(\mathrm{conc})$ & $\mathrm{Ea}(\mathrm{kJ} / \mathrm{mol})$ & $\Delta \mathrm{H}(\mathrm{kJ} / \mathrm{mol})$ & $\Delta \mathrm{S}\left(\mathrm{kJ} / \mathrm{mol}^{-1} \mathrm{~K}^{-1}\right)$ & \multicolumn{2}{l}{$\Delta \mathrm{G} \times 10^{3}(\mathrm{~kJ} / \mathrm{mol})$} \\
\cline { 5 - 6 } & & & & $303.15 \mathrm{~K}$ & $333.15 \mathrm{~K}$ \\
\hline Blank & $65,041.56$ & 61.90 & 11.49 & - & - \\
50 & $75,587.88$ & 72.11 & 40.41 & -45.21 & -46.16 \\
1000 & $76,633.12$ & 73.39 & 39.84 & -41.92 & -44.22 \\
\hline
\end{tabular}


obtained and from the slope $\left(-\frac{\Delta H}{2.303 R T}\right)$ and intercept $\left[\log \left(\frac{\mathrm{R}}{\mathrm{Nh}}\right)+\left(\frac{\Delta \mathrm{S}}{2.303 \mathrm{R}}\right)\right]$ of the linear plot, the numerical values of $\Delta \mathrm{H}$ and $\Delta \mathrm{S}$, respectively were obtained. The experimentally obtained values of $\Delta \mathrm{H}$ and $\Delta \mathrm{S}$ are presented in Table 3. The values of activation energy and enthalpy of adsorption in presence of green synthesized surfactant are comparatively lower than in $1 \mathrm{M} \mathrm{HCl}$ alone. This change in the value of $E_{a}$ in presence of green additive may be due to the modification of the mechanism of the corrosion reaction in presence of adsorbed additive molecules over surface. It is generally seen that higher values of $E_{a}$ in presence of corrosion inhibitor additives support physiosorption mechanism whereas an unchanged or lower value of $E_{a}$ for inhibited systems compared to the blank is indicative of chemisorption mechanism. The inhibitor causing an increase in the values of $\mathrm{E}_{\mathrm{a}}$ compared to blank retard the corrosion at ordinary temperature, but the inhibition is diminished at elevated temperature. In the present investigation the value of $E_{a}$ in presence of $A D H$ is higher compared to the blank and hence supports physical adsorption mechanism.

The enthalpy of adsorption also increases in presence of the ADH compared to the free acid solution, this further support the mechanism of physiosorption. The values of $\Delta S$ are positive which indicates a decrease in the system order in the presence of $A D H$, indicating that the adsorption of ADH on low carbon steel surface is exothermic.

The free energy of adsorption, $\Delta G_{\text {ads }}$ is related to $K_{\text {ads }}$ values with the following equation:

$K_{\text {ads }}=\frac{1}{55.55} \exp \left(-\frac{\Delta G_{a d s}}{R T}\right)$

The calculated values of $\Delta \mathrm{G}_{\text {ads }}$ at 303.15 and $333.15 \mathrm{~K}$ for three ADH concentrations are presented in Table 3. The negative values of $\Delta \mathrm{G}_{\mathrm{ads}}$ indicate the spontaneous adsorption of the ADH on steel surface. It is an established fact that values of $\Delta \mathrm{G}_{\mathrm{ads}}$ around $-20 \mathrm{~kJ} \mathrm{~mol}^{-1}$ or less indicates physiosorption. The values of $\Delta \mathrm{G}_{\text {ads }}$ around $-40 \mathrm{~kJ} \mathrm{~mol}^{-1}$ or more are considered as chemisorptions. In the present investigation the values of $\Delta \mathrm{G}_{\text {ads }}$ are between -39.82 and $-46.16 \mathrm{~kJ} \mathrm{~mol}^{-1}$ suggesting a mixed type of adsorption involving both physiosorption and chemisoprtion. However, the variation in the values of \% IE with temperature and higher values of $E_{a}$ and $\Delta H$ in presence of $A D H$ compared to blank suggest major contribution of physiosorption in the adsorption process.

\subsection{Potentiodynamic polarization measurements}

The cathodic and anodic polarization curves for carbon steel in $1 \mathrm{M} \mathrm{HCl}$ as uninhibited, $\mathrm{ADH}$ and $\mathrm{ADH}-\mathrm{ZnO}$
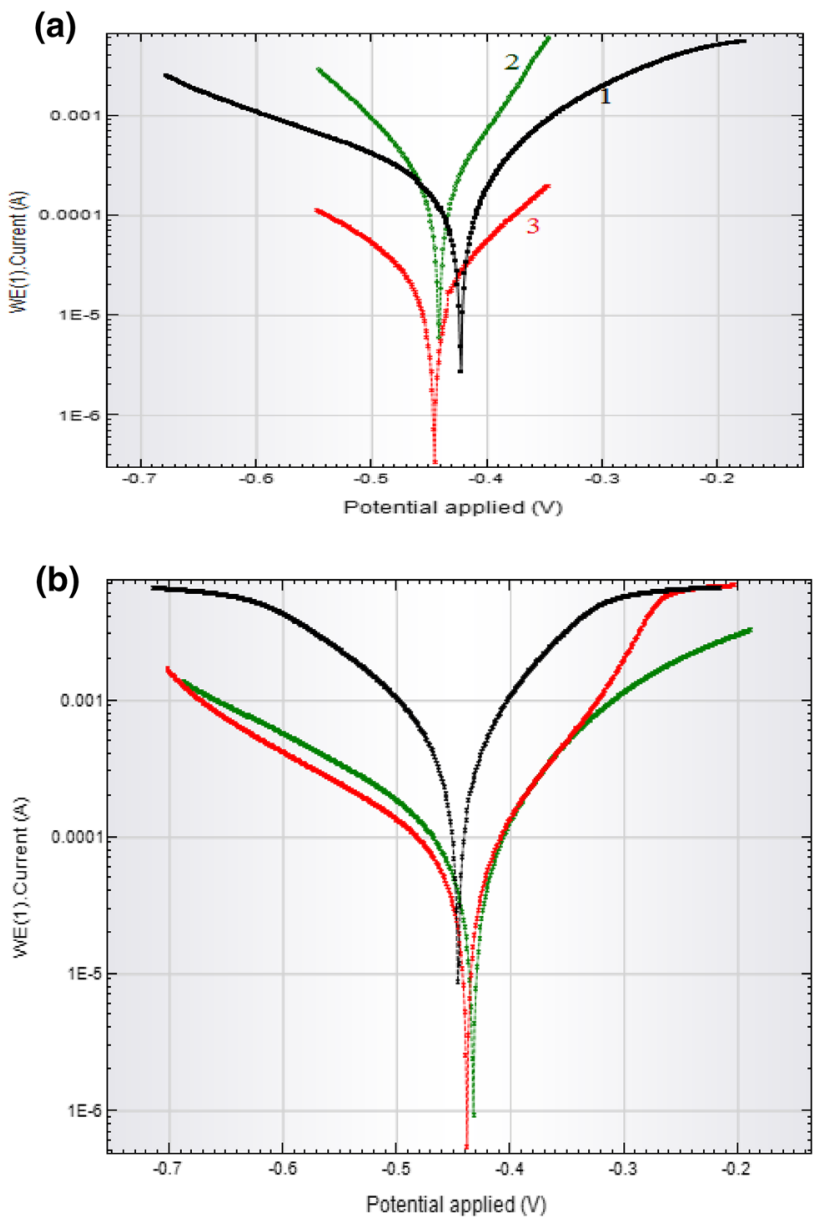

Fig. 7 Potentiodynamic polarization curves for carbon steel in $1 \mathrm{M}$ $\mathrm{HCl}$ : a ADH and b ADH-ZnO (1) Blank (2) ADH (10 ppm), (3) ADH (1000 ppm)

inhibited acid solution at $303.15 \mathrm{~K}$ were obtained and are shown in Fig. 7a, b. The values of electrochemical corrosion kinetic parameters as obtained by extrapolation of the tafel lines e.g., corrosion potential $\left(\mathrm{E}_{\text {corr }}\right)$ corrosion current density ( $\mathbf{i}_{\text {corr }}$ ) and cathodic and anodic Tafel slopes $\left(\beta_{c^{\prime}} \beta_{a}\right)$ are shown in Table 4 . The \% IE was calculated using the Eq. 3. The study of electrochemical data reveals that the values of $\mathbf{i}_{\text {corr }}$ decreases in presence of ADH in comparison with the bank acid solution. As expected both the anodic and cathodic reactions of carbon steel corrosion are inhibited in presence of $A D H$ inhibitor, while more inhibition efficiency was obtained from $\mathrm{ADH}-\mathrm{ZnO}$. It can be seen from the curves that both anodic and cathodic reactions are affected by the surfactants. This is suggestive of the fact that addition of $\mathrm{ADH}$ and $\mathrm{ADH}-\mathrm{ZnO}$ reduced the anodic dissolution of steel and also suppressed the hydrogen evolution reaction. The values of $\mathrm{E}_{\text {corr }}$ in the presence of $\mathrm{ADH}$ and $\mathrm{ADH}-\mathrm{ZnO}$ shift to more positive values compared to the blank but no regular shift in $\mathrm{E}_{\text {corr }}$ is detected. The shape of the polarization curves in the inhibited and 
Table 4 Potentiodynamic polarization parameters of $\mathrm{ADH}$ and $\mathrm{ADH}-\mathrm{ZnO}$ at $303.15 \mathrm{~K}$

\begin{tabular}{llccccc}
\hline $\begin{array}{l}\text { Surfactant con- } \\
\text { centration }(\mathrm{ppm})\end{array}$ & $\mathrm{E}_{\text {corr }}(\mathrm{mV} / \mathrm{SCE})$ & $\mathrm{i}_{\text {corr }}\left(\mu \mathrm{A} / \mathrm{cm}^{2}\right)$ & $\beta_{\mathrm{a}}(\mathrm{mV} / \mathrm{dec})$ & $\beta_{\mathrm{c}}(\mathrm{mV} / \mathrm{dec})$ & $\mathrm{CR}(\mathrm{mmpy})$ & $\% \mathrm{IE}$ \\
\hline Blank & -429.28 & 322.71 & 330.23 & 147.82 & 3.75 & \\
$A D H$ & & & & & & \\
50 & -442.19 & 188.83 & 82.71 & 65.99 & 2.19 & 41.49 \\
1000 & -445.15 & 36.01 & 195.10 & 135.68 & 0.42 & 88.84 \\
Blank & -446.32 & 747.15 & 200.57 & 145.85 & 8.68 & \\
$A D H-Z n O$ & & & & & & \\
50 & -442.14 & 177.08 & 314.62 & 163.25 & 2.06 & 76.00 \\
1000 & -438.57 & 63.51 & 198.03 & 94.35 & 0.74 & 91.50 \\
\hline
\end{tabular}

Table 5 Some important theoretical parameters for ADH by B3LYP/6-311G(d,p)

\begin{tabular}{|c|c|}
\hline Parameters & B3LYP/6-311G(d,p) \\
\hline SCF minimum energy $(\mathrm{kcal} / \mathrm{mol})$ & $1,202,977.556$ \\
\hline \multicolumn{2}{|c|}{ Field independent dipole moment (debye) } \\
\hline$\mu_{x}$ & -0.9872 \\
\hline$\mu_{y}$ & 4.1381 \\
\hline$\mu_{z}$ & 2.1012 \\
\hline$\mu$ & 4.7449 \\
\hline \multicolumn{2}{|c|}{ Frontier molecular orbital energies (eV) } \\
\hline$E_{L U M O+1}$ & 0.14 \\
\hline$E_{\text {LUMO }}$ & -0.22 \\
\hline$E_{\text {Номо }}$ & -6.43 \\
\hline$E_{\text {HOMO-1 }}$ & -7.53 \\
\hline$G A P=E_{L U M O}-E_{\text {HOMO }}$ & 6.21 \\
\hline Excitation energy (HOMO-LUMO) & 5.36 \\
\hline \multicolumn{2}{|l|}{ Global reactivity descriptors } \\
\hline Ionization potential, I (eV) & 6.43 \\
\hline Electron affinity, $A(\mathrm{eV})$ & 0.22 \\
\hline Electronegativity, $\chi$ & 3.33 \\
\hline Chemical potential, $\mu$ & -3.33 \\
\hline Electrophilicity, $\omega$ & 1.78 \\
\hline Hardness, $\eta$ & 3.11 \\
\hline Softness, S & 0.16 \\
\hline$\Delta N$ & 0.59 \\
\hline$\Delta E$ & -0.78 \\
\hline TNC & -12.54 \\
\hline Molar volume $\left(\mathrm{cm}^{3} / \mathrm{mol}\right)$ & 493.66 \\
\hline
\end{tabular}

uninhibited solutions are not substantially different. The $E_{\text {corr }}$ values, suggesting that the inhibitors acts a mixed type. The addition of ADH and ADH-ZnO only decreases the $\mathrm{i}_{\text {corr }}$ but does not gave any trend in other parameters of the polarization behaviour. The values of \%IE as obtained from potentiodynamic polarization measurements are consistent with the values of $\%$ IE obtained from weight loss measurements.

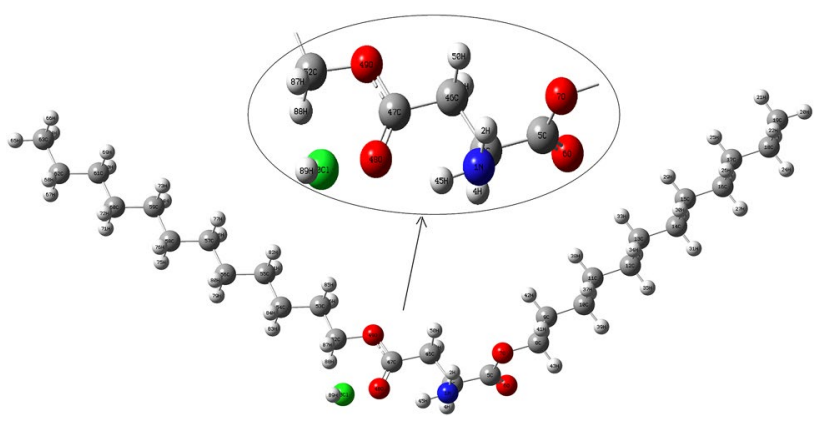

Fig. 8 Optimized geometry of the compound ADH

\subsection{Theoretical studies}

The mechanism of corrosion inhibition of the compound is studied extensively by quantum chemical methods [38-42]. In the present study, structure, IR spectra and various molecular properties like molecular energy, field independent dipole moment, atomic charges (Natural and Mullikan population), frontier molecular orbital energies, HOMO-LUMO gap, HOMO-LUMO excitation energy, local and global chemical reactivity indices, molar volume, fraction of electron transferred from inhibiter to iron metal surface $(\Delta N)$, summation of the total negative charges on atoms over the skeleton of the molecule (TNC) and the change in energy due to electronic donation and back donation are presented to study the corrosion inhibition efficiency of ADH compound by DFT calculations. These molecular parameters, collected in Table 5, may be responsible for the inhibitor efficiency. The optimized geometry of the present compound is shown in Fig. 8.

In order to prevent metal by corrosion, the inhibitor molecule is used and it interacts with metal surface through their active sites (excess or deficiency of charge). The active sites were analysed for the present molecule using some important parameters like atomic charges, MEP, HOMO, LUMO, global and local reactivity descriptors. 
Fig. 9 Variation of natural and mulliken charges

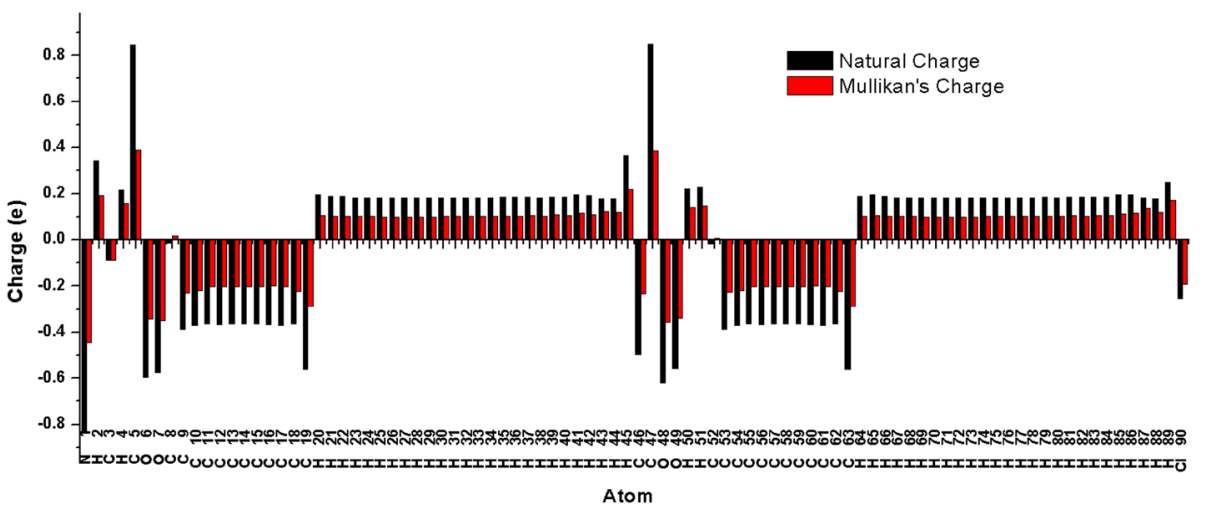

The atomic charges can be treated as local electron densities in the molecule which were computed for the present molecule using natural as well as Mullikan population analysis. The variation of charges in molecule is presented in Fig. 9. These quantities help in explaining electrostatic interactions and molecular polarity as well as in computing local chemical reactivity descriptors like Fukui's functions [38].

The Fukui's functions are exploited in determining the reactivity of molecule towards another chemical species. These local indices help in detection of active sites over the molecule. In general, Mullikan's charges appear weaker than Natural charges [28]. In this study, the natural charges are used to obtain Fukui indices and also to understand the adsorption process of corrosion inhibitors to the metal surface. The atomic charge in molecule play important role to simulate the activation sites of the inhibitors involved in adsorption with the metal surface [43]. The corrosion inhibitor molecule with the sites of more negative atomic charge shows more reactivity toward the metal surface as these atoms easily donate the electron to the unoccupied $d$-orbital of the metal [44]. Most of the carbon atoms in molecule have shown strong negative charge except $\mathrm{C5}$ and $\mathrm{C} 47$. The atoms $\mathrm{C} 5$ and $\mathrm{C} 47$ are found with maximum positive charge among others as they are connected with atoms that possess strong negative charges (high electronegativity). The nitrogen atom in molecule possesses strongest negative charge among all atoms and it could be centre for adsorption [45]. Thus, the strong negative charges on atoms N1, 07, 06, 048 and 049 in molecule indicate that the molecule under investigation may efficiently inhibit the corrosion of the metal surface through adsorption mechanism via active sites (N1, O7, O6, 048 and 049) of the present inhibitor. The calculated charges have shown that the active sites in the present inhibitor are over the oxygen and nitrogen atoms by which inhibitor may adsorb on the metal surface. Total negative charge (TNC) for the present molecule is found very high which reflects its high ionic reactivity as well as high inhibition efficiency.
The dipole moment of the present molecule was computed about 4.74 Debye which indicates its polar character. The dipole moment defines the charge movement across the molecule. It was reported that the inhibition efficiency increases with the decrease in the dipole moment of the some investigated corrosion inhibitors. Contrarily, some authors have also reported that the high value of dipole moment is responsible for the high inhibition efficiency [39, 46, 47].

The frontier molecular orbitals (HOMO and LUMO) have been used to define global chemical reactivity descriptors and the kinetic stability of the inhibitor. Global reactivity descriptors are obtained using the equations that relate the descriptors with frontier molecular orbital energy and can be found in various literatures [48]. The chemical hardness and softness define the stability and reactivity respectively of the compound. If a molecule has large or small HOMO-LUMO gap, then it is hard (less reactive/ more stable) or soft (more reactive/less stable) respectively. Similarly the greater the values of chemical potential or electronegativity the less stable or more reactive is the chemical system [49]. The descriptor electrophilicity define the capacity of a chemical system to accept electronic charge from the other chemical species. The energy value of HOMO shows the ability to donate the electron while of LUMO defines the ability to accept the electron of reacting species. The HOMO, LUMO energy values, their gap and various reactivity descriptors have been depicted in Table 1. The high value of HOMO $(-6.43 \mathrm{eV})$ and the low value of LUMO $(-0.22 \mathrm{eV})$ were found for the present molecule. The high HOMO energy value defines the high ionization potential of the inhibitor therefore it has the better adsorption and inhibition efficiency. On the other hand, the low value of LUMO (electron affinity) of inhibitor describes the strong ability to accept the free electrons from metal surface. Thus, both energy values explain the strong strength of the adsorption of molecule with metal surface and support to high inhibition efficiency. The HOMO-LUMO gap for present molecule is found to be $6.21 \mathrm{eV}$ while corresponding excitation energy is $5.36 \mathrm{eV}$ 


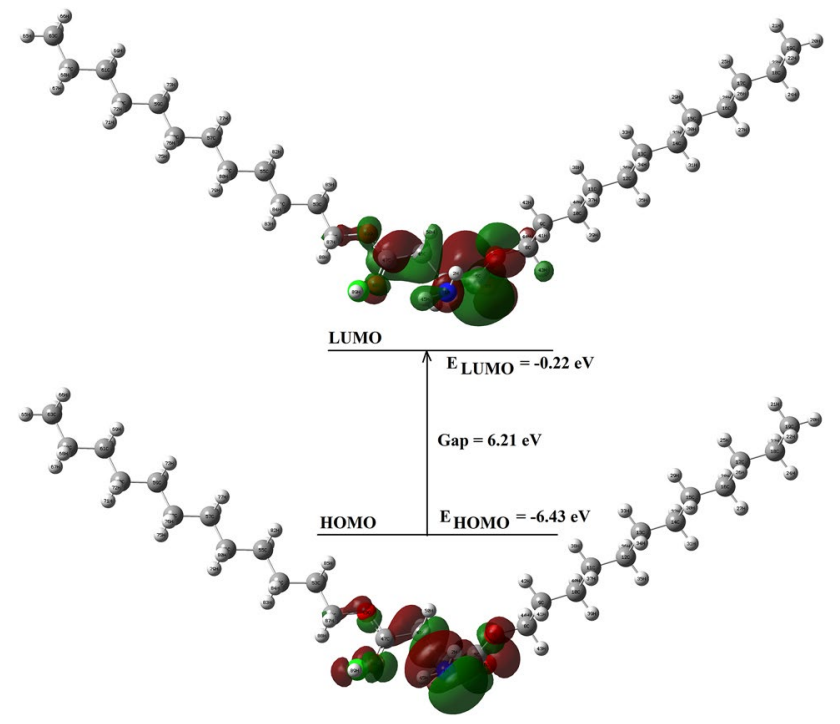

Fig. 10 Spatial plot of HOMO and LUMO along with energy and gap

(at TD-B3LYP/6-311G $(\mathrm{d}, \mathrm{p})$ ) that means the high kinetic stability, less reactivity and less inhibitor efficiency which is the contradictory to the statement made on high inhibitor efficiency based on HOMO and LUMO energy values. If the HOMO and LUMO energy values are key parameter then the present molecule is of high inhibition efficiency and if the gap is then it is of less inhibition efficiency. The spatial plot of HOMO and LUMO along with energy and gap is presented in Fig. 10.

The HOMO and LUMO are mostly occupied over the $\mathrm{C}=\mathrm{O}, \mathrm{NH}_{2}$ and $\mathrm{H}-\mathrm{Cl}$ in present molecule and therefore these regions may take part in adsorption with metal surface. The parameter $\Delta N$ explains the electron transferred from the inhibitor to the metal (iron) surface (Table 1). As per Lukovits's study, if the value of $\Delta N$ is less than 3.6 then the efficiency of inhibitor will increase with increasing its electron donating ability [50]. The molecular volume of the present inhibitor has been also computed and its large value represents the high inhibition efficiency. Gomez et al. have defined electronic donation and back donation process which governs the interaction of molecule with metal surface [51]. Both processes, charge transfer to the molecule and from the molecule, occur simultaneously and the energy difference is defined by the relation $\Delta E=-\frac{\eta}{4}$. If $\eta>0, \Delta E<0$ then the back donation from the molecule to metal surface is favourable [44].

Molecular electrostatic potential mapping on to total electron density plot was obtained for the investigated molecule to define the sites of electrophilic attack in the adsorption process with metal surface (Fig. 11).

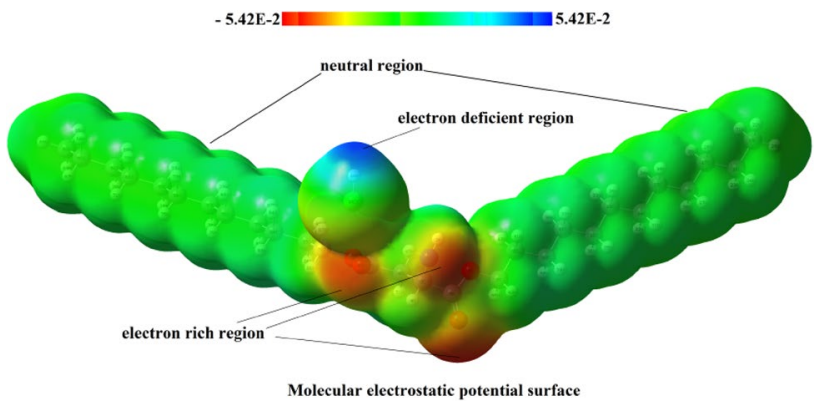

Fig. 11 Molecular electrostatic potential mapping

The electrostatic potential surfaces over the molecule have been defined by the colour coding; the red and blue colour shows respectively the electron rich and deficient regions while green colour represents the neutral part of the molecule. The regions over the oxygen and nitrogen atoms, as shown by red colour in Fig. 11, may be the preferable sites of electrophilic attack.

The local reactivity descriptors were computed using condensed Fukui's functions obtained by natural population analysis. The definitions of local descriptors are necessary to study the site-selectivity or site-reactivity of a chemical system. The largest values of Fukui functions for the sites in chemical system show high reactivity for corresponding nucleophilic or electrophilic attacks. The Fukui functions based on natural charges for present molecule are presented in Fig. 12.

From Fig. 12, it is concluded that for present compound the high reactivity sites for the nucleophilic attack are $\mathrm{H} 89$, $\mathrm{Cl} 90, \mathrm{C} 47$ and the strong electrophilic reactivity sites are $\mathrm{N} 1$ and $\mathrm{O} 6$ while the sites for free radical attacks are $\mathrm{N} 1$, $\mathrm{H} 89$ and $\mathrm{O6}$. To examine the probable sites of the inhibitor that will accept or donate charge from or to the metal surface, one must see for the largest values of $f+$ and $\mathrm{f}-$ respectively.

The local softness and electrophilicity condensed to an atom location were also calculated at same level of theory to define the reactivity of atoms in molecule. The maximum value of $s+$ and $\omega+$ represent the most electrophilic site while the maximum values of $s-$ and $\omega$ - show the most nucleophilic site in a chemical system. The comparisons between local reactivity indices for each atom in present are represented by Fig. 13 .

\subsection{Surface analysis (SEM and TEM)}

Furthermore, the morphology of the synthesized Surfactant-ZnO we as determined through SEM and HRTEM. Figure 14 shown SEM image of Surfactant, clearly 
Fig. 12 Fukui functions based on natural charges for present molecule

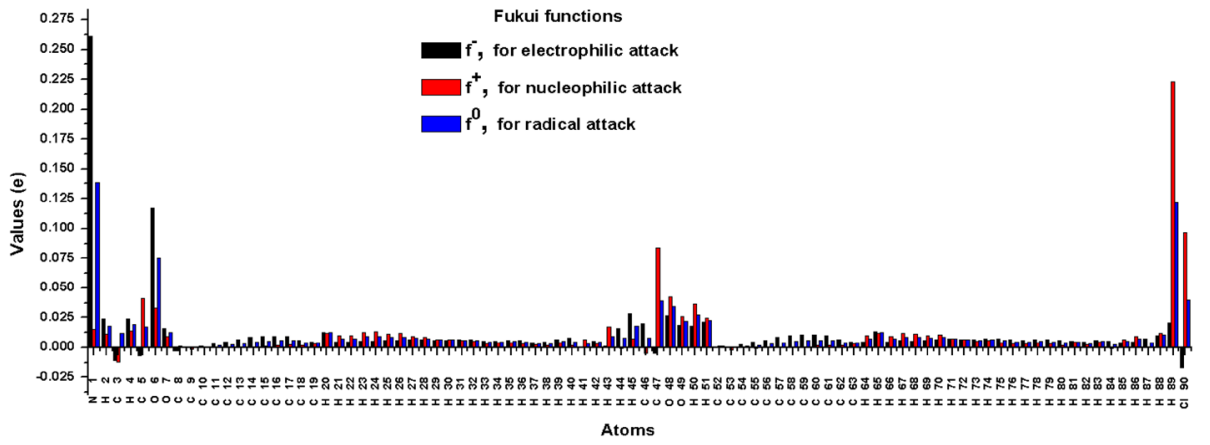

Local Softness

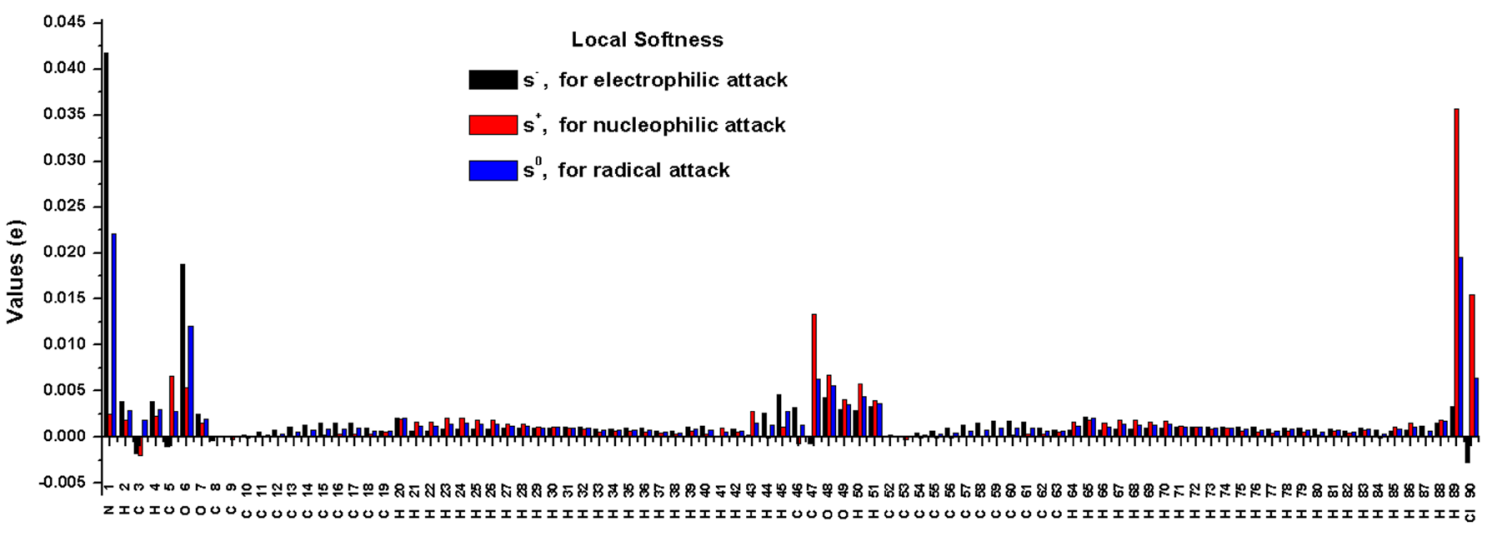

Atoms

(a)

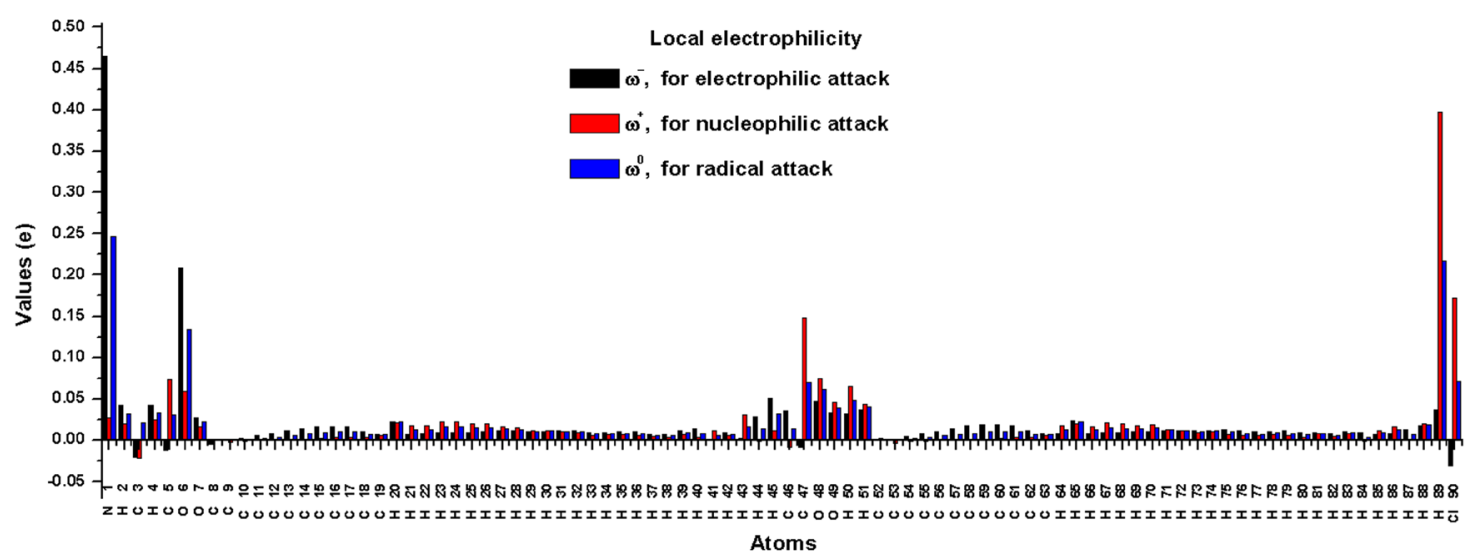

(b)

Fig. 13 Comparisons between local reactivity indices for each atom in present

hierarchical microstructure on the scale of $5 \mu \mathrm{m}$ that were connected through a large number of the nanoparticle. Figure $14 \mathrm{~b}$ corresponding energy-dispersive X-ray spectrum (EDAX) confirmed the presence of element $C$, $\mathrm{S}, \mathrm{N}, \mathrm{Zn}$ and $\mathrm{O}$ respectively. Figure $14 \mathrm{c}$, reveal a HRTEM image of the synthesized Surfactant-ZnO sample is found composed of arranging flower sphere established by interconnected nanocrystal on the scale of $100 \mathrm{~nm}$. Additionally, HRTEM image reveals the Surfactant-ZnONPs flower spheres are fabricated of firmly packed nanocrystals that are strongly interconnected with each other, proposing effective charge transport properties, and showing multiple pores structured by interparticle voids, promoting high internal surface area for corrosion property. 


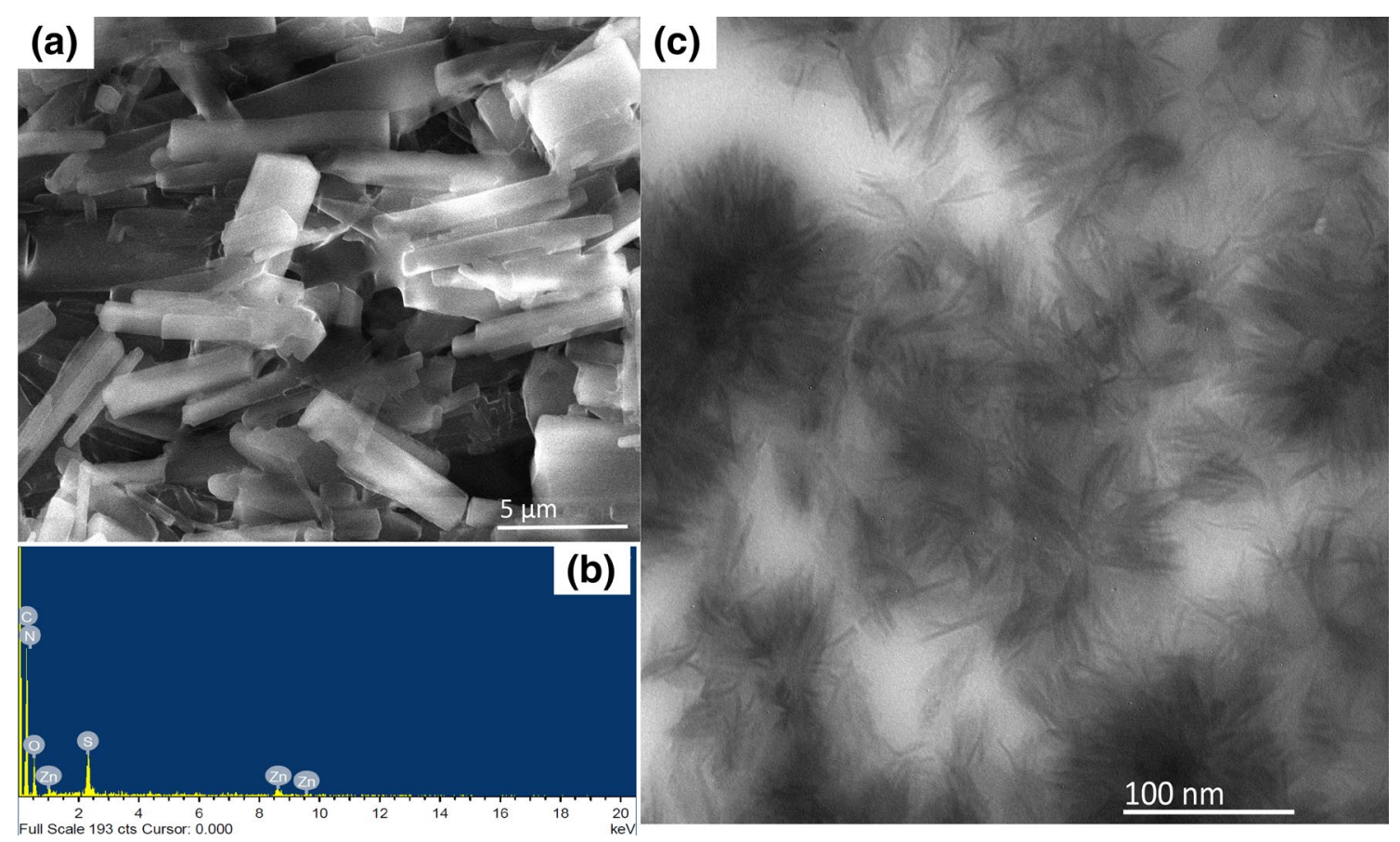

Fig. 14 SEM (a), EDAX (b) and HRTEM (c) of the synthesized ADH-ZnO Np

\subsubsection{SEM and EDAX studies}

The scanning electron microscope images were obtained to establish the fact that corrosion inhibition of carbon steel in $1 \mathrm{M} \mathrm{HCl}$ is due to the formation of a protective film by the adsorbed ADH molecules. The SEM photomicrographs of the polished carbon steel surface and steel surface exposed to $1 \mathrm{M} \mathrm{HCl}$ in absence and presence of ADH has been depicted in Fig. 15a-c. Figure 15a shows the surface morphology of the sample before immersion in $1 \mathrm{M} \mathrm{HCl}$ solution. Except the marks of the scratches which had arisen during polishing with emery papers the surface shows a characteristic freshly polished steel surface which is free from any noticeable defects such as cracks and pits. Figure $15 \mathrm{~b}$ shows the SEM photomicrograph of steel surface obtained after immersion in uninhibited $1 \mathrm{M}$ $\mathrm{HCl}$. A damaged and heterogeneous surface is observed as a result of severe corrosion of low carbon steel by the aggressive acid solution. Figure $15 \mathrm{c}$ shows the photomicrograph of the low carbon steel surface immersed for the same period of time in $1 \mathrm{M} \mathrm{HCl}$ containing $1000 \mathrm{ppm}$ of $\mathrm{ADH}$. The surface heterogeneity is considerably decreased in the presence of inhibitor; the surface clearly resembles with the surface of the mild steel before immersion in acid solution. The decrease in the surface heterogeneity would have been caused by the deposition of the ADH molecules on the carbon steel surface which protected the steel surface from the attack of corrosive medium. The scratches formed during the polishing were adequately covered well by the ADH molecules.

The EDAX spectrum of the polished mild steel surface and steel surface exposed to $1 \mathrm{M} \mathrm{HCl}$ in absence and presence of $A D H$ were obtained and the results are shown in Fig. 15a-c. The EDAX spectrum was recorded in order to determine the content of iron and other elements on the steel surface in absence and presence of inhibitor. Figure 15a represents the EDAX profile of polished low carbon steel, which revealed that the surface was free from any corrosion product in the absence of immersion in acid solution. In case of carbon steel exposed to $1 \mathrm{M} \mathrm{HCl}$ the iron content on the surface was appreciably reduced in comparison to the polished mild steel due to formation of corrosion products; presence of oxygen was also revealed on the surface (Fig. 15b). Figure 15c shows EDAX profile of carbon steel specimen immersed for the same period of time in $1 \mathrm{M} \mathrm{HCl}$ containing $1000 \mathrm{ppm}$ of $\mathrm{ADH}$. The spectrum showed higher concentration of iron presumably due to lowering in the extent of corrosion in presence of ADH. 
Fig. 15 SEM and EDAX photomicrographs of carbon steel samples, a Polished, $\mathbf{b}$ dipped in $1 \mathrm{M} \mathrm{HCl}$, c dipped in $\mathrm{ADH}$ inhibited $1 \mathrm{M} \mathrm{HCl}$

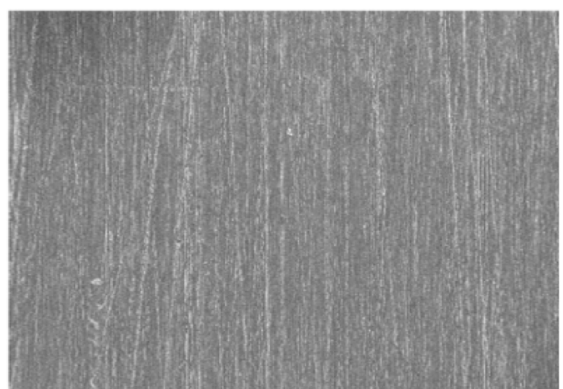

(a)

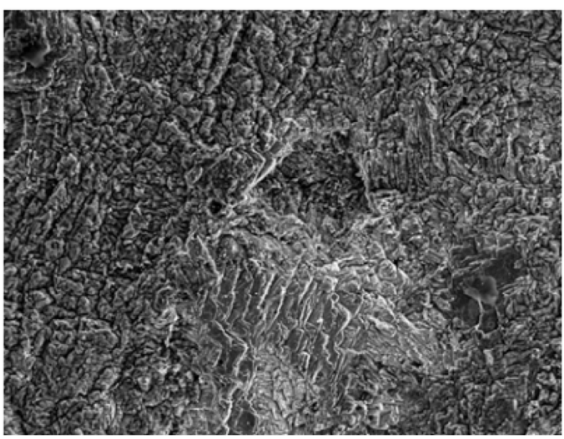

(b)

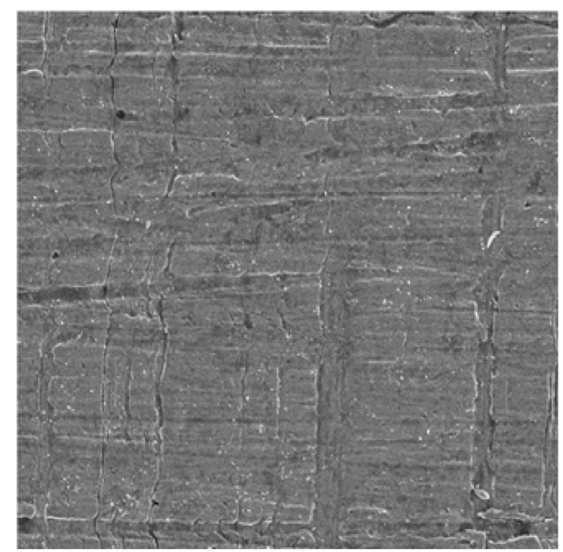

(c)
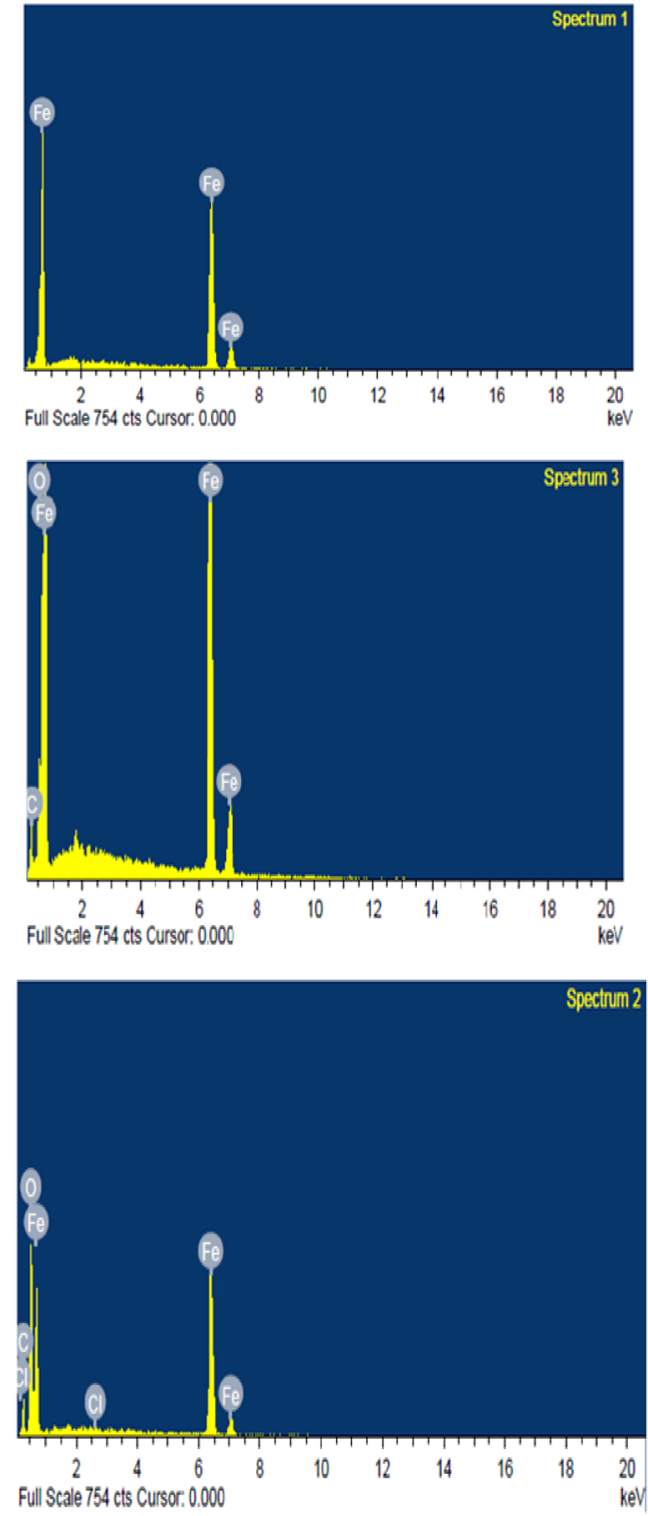

\section{Conclusion}

From the obtained results the following conclusions can be deduced:

1. Biodegradable amino acid derived surfactant, aspartic di-dodecyl ester hydrochloride acid acts as good corrosion inhibitor for low carbon steel in $1 \mathrm{M} \mathrm{HCl}$ solution. The inhibition efficiency increases with increase in the inhibitor concentration while it decreases at high temperature from 303.15 to $333.15 \mathrm{~K}$, which is suggestive of physical adsorption.
2. Nanocomposite of biodegradable amino acid surfactant with $\mathrm{ZnO}$ worked best with better corrosion inhibition efficiency at $303.15 \mathrm{~K}$.

3. The experimental data obtained from gravimetric measurements suggest corrosion inhibition by adsorption mechanism and fit well the Langmuir adsorption isotherm at all the concentrations and temperatures studied.

4. Thermodynamic parameters revealed that the adsorption process is spontaneous.

5. The results of potentiodynamic polarization measurements indicate that inhibitor acts as mixed type inhibitor. 
6. The computed values of the quantum chemical parameters support the results of weight loss and potentiodynamic measurements.

7. The SEM studies showed smoother surface of low carbon steel in presence of inhibitor, This further confirms the results of weight loss and electrochemical measurements. EDAX results confirmed the formation of an absorption layer in presence of inhibitor.

Acknowledgements This work was supported by the DST-PURSE Phase-II Project funded to Aligarh Muslim University.

\section{Compliance with ethical standards}

Conflict of interest The authors declare that they have no conflict of interest.

Human and animal rights No human population or animal is involved in this paper.

\section{References}

1. Bognolo G (1999) Biosurfactants as emulsifying agents for hydrocarbons. Coll Surf A Physicochem Eng Asp 152:41-52

2. Migahed MA, Al-Sabagh AM (2009) Beneficial role of surfactant as corrosion inhibitors in petroleum industry: a review article. Chem Eng Comm 196:1054-1075

3. Wang WL, Free ML (2004) Prediction and measurement of corrosion inhibition of mild steel using nonionic surfactants in chloride media. Corros Sci 46:2601-2611

4. Atia AA, Saleh MM (2003) Inhibition of acid corrosion of steel using cetylpyridinium chloride. J Appl Electrochem 33:171-177

5. Saleh M, Atia AA (2006) Effects of structure of the ionic head of cationic surfactant on its inhibition of acid corrosion of mild steel. J Appl Electrochem 26:899-905

6. Atta AM, El-Mahdy GA, Ismail HS, Al-Lohedan HA (2012) Effects of water soluble rosin on the corrosion inhibition of carbon steel. Int J Electrochem Sci 7:11834-11846

7. Atta AM, El-Mahdy GA, Al-Azhary AA, Al-Lohedan HA (2013) Experimental investigation and theoretical approach on water soluble rosin as corrosion inhibitors. Int J Electrochem Sci 8:1295-1307

8. Quraishi MA, Sardar R (2002) Corrosion inhibition of mild steel in acid solutions by some aromatic oxadiazoles. Mater Chem Phys 78:425-431

9. Bastidas JM, Pinilla P, Polo JL, Miguel S (2003) Copper corrosion inhibition by triphenylmethane derivatives in sulphuric acid media. Corros Sci 45:427-449

10. Migahed MA, Abdul-Raheim AM, Atta AM, Brostow W (2010) Synthesis and evaluation of a new water soluble corrosion inhibitor from recycled poly(ethylene terphethalate). Mater Chem Phys 121:208-214

11. Farguez $\mathrm{P}$, Avilés $\mathrm{F}$, Oliva Al (2008) Mechanical properties of gold nanometric films onto a polymeric substrate. Surf Coat Technol 202:1556-1563

12. Sabzi M, Mirabedini SM, Zohuriaan-Mehr J, Atai M (2009) Surface modification of $\mathrm{TiO}_{2}$ nano-particles with silane coupling agent and investigation of its effect on the properties of polyurethane composite coating. Prog Org Coat 65:222-228
13. Yiu-Wing M, Zhong-Zhen $Y$ (2006) Polymer nanocomposites. Wood head Publishing Limited, Cambridge

14. Sardar S, Kar P, Remita H, Liu B, Lemmens P, Kumar PS (2015) Enhanced charge separation and FRET at hetero junctions between semiconductor nanoparticles and conducting polymer nanofibers for efficient solar light harvesting. Sci Rep 5:17313. https://doi.org/10.1038/srep17313

15. Karthikeyan B, Pandiyarajan T, Mangalaraja RV (2016) Enhanced blue light emission in transparent ZnO:PVA nanocomposite free standing polymer films. Spectrochim Acta A Mol Biomol Spectrosc 152:485-490. https://doi.org/10.1016/j.saa.2015.07.053

16. Gao G, Wu H, He R, Cui D (2010) Corrosion inhibition during synthesis of $\mathrm{Cu}_{2} \mathrm{O}$ nanoparticles by 1,3-diaminopropylene in solution. Corros Sci 52:2804-2812

17. Zhang X, Wang F, Du Y (2007) Effect of nano-sized titanium powder addition on corrosion performance of epoxy coatings. Surf Coat Technol 201:7241-7245

18. Zubillaga O, Cano FJ, Azkarate I, Molchan IS, Thompson GE, Skeldon $\mathrm{P}$ (2009) Anodic films containing polyaniline and nanoparticles for corrosion protection of AA2024T3 aluminium alloy. Surf Coat Technol 203:1494-1501

19. Behzadnasab M, Mirabedini SM, Kabiri K, Jamali S (2011) Corrosion performance of epoxy coatings containing silane treated $\mathrm{ZrO}_{2}$ nanoparticles on mild steel in $3.5 \% \mathrm{NaCl}$ solution. Corros Sci 53:89-98

20. Zhang Z, Chen S, Ren H, Zhou J (2009) Protection of iron against corrosion by coverage with Au nanoparticles and $n$-hexylthiol mixed films. Appl Surf Sci 255:4950-4954

21. http://publications.lib.chalmers.se/records/fulltext/155389.pdf

22. Shoeb M, Braj RS, Javed AK, Wasi K, Brahma NS, Harikesh BS, Alim HN (2013) ROS-dependent anticandidal activity of zinc oxide nanoparticles synthesized by using egg albumen as a biotemplate. Adv Nat Sci Nanosci Nanotechnol 4:035015

23. Khan YA, Singh BR, Ullah R, Shoeb M, Naqvi AH, Abidi SMA (2015) Anthelmintic effect of biocompatible zinc oxide nanoparticles (ZnO NPs) on gigantocotyle explanatum, a neglected parasite of indian water buffalo. PLoS ONE 10:e0133086

24. Mobin M, Masroor S (2014) Adsorption and corrosion inhibition behavior of Schiff base-based cationic gemini surfactant on mild steel in formic acid. J Dispers Sci Technol 25:535-545

25. Becke A (1988) Phys Rev A 38:3098

26. Frisch GWTMJ, Schlegel HB, Scuseria GE, Robb MA, Cheeseman JR, Scalmani G, Barone V, Mennucci B, Petersson GA, Nakatsuji $\mathrm{H}$, Caricato $\mathrm{M}$, Li X, Hratchian HP, Izmaylov AF, Bloino J, Zheng G, Sonnenberg JL, Hada M, Ehara M, Toyota K, Fukuda R, Hasegawa J, Ishida M, Nakajima T, Honda Y, Kitao O, Nakai $\mathrm{H}$, Vreven T, Montgomery JA Jr, Peralta JE, Ogliaro F, Bearpark M, Heyd JJ, Brothers E, Kudin KN, Staroverov VN, Kobayashi R, Norm J, Raghavachari K, Rendell A, Burant JC, lyengar SS, Tomasi J, Cossi M, Rega N, Millam JM, Klene M, Knox JE, Cross JB, Bakken V, Adamo C, Jaramillo J, Gomperts R, Stratmann RE, Yazyev O, Austin AJ, Cammi R, Pomelli C, Ochterski JW, Martin RL, Morokuma K, Zakrzewski VG, Voth GA, Salvador P, Dannenberg JJ, Dapprich S, Daniels AD, Farkas Ö, Foresman JB, Ortiz JV, Cioslowski J, Fox DJ (2009) Wallingfort CT, Edition

27. Dennington R, Keith T, Millam J (2009) GaussView, Ver. 5. Semichem Inc., Shawnee Mission, KS

28. Alam MJ, Ahmad S (2014) Quantum chemical and spectroscopic investigations of 3-methyladenine. Spectrochim Acta A Mol Biomol Spectrosc 128:653-664

29. Socrates $G$ (1980) Infrared characteristic group frequencies, 3rd edn. Wiley, New York

30. http://staff.aub.edu.lb/ tg02/IR.pdf

31. Alam MJ, Ahmad S (2012) Spectrochimica Acta A Mol Biomol Spectrosc 96:992 
32. Alam MJ, Ahmad S (2015) FTIR, FT-Raman, UV-Visible spectra and quantum chemical calculations of allantoin molecule and its hydrogen bonded dimmers. Spectrochimica Acta A Mol Biomol Spectrosc 136:961-978

33. Navarrete JTL, Hernández V, Ramírez FJ (1994) Ir and Raman spectra of L-aspartic acid and isotopic derivatives. Biopolymers 34:1065-1077

34. Susi H, Byler DM, Gerasimowicz WV (1983) Vibrational analysis of amino acids: cysteine, serine, $\beta$-chloroalanine. J Mol Struct 102:63-79

35. Rajkumar BJM, Ramakrishnan V, Rajaram RK (1998) Infrared and Raman spectra of dl-aspartic acid nitrate monohydrate. Spectrochim Acta A Mol Biomol Spectrosc 54:1527-1532

36. Mobin M, Masroor S (2012) Alkanediyl-a, $\omega$-bis (dimethyl cetylammonium bromide) gemini surfactants as novel corrosion inhibitors for mild steel in formic acid. Mater Res 15(6):837-847

37. Mobin M, Masroor S (2012) Cationic gemini surfactants as novel corrosion inhibitor for mild steel in $1 \mathrm{M} \mathrm{HCl}$. Int J Electrochem Sci 7:6920-6940

38. Ameh PO, Koha PU, Eddy NO (2015) Experimental and quantum chemical studies on the corrosion inhibition potential of phthalic acid for mild steel in $0.1 \mathrm{M} \mathrm{H}_{2} \mathrm{SO}_{4}$. Chem Sci J 6:1-8

39. Kumar S, Sharma D, Yadav P, Yadav M (2013) Experimental and quantum chemical studies on corrosion inhibition effect of synthesized organic compounds on $\mathrm{N} 80$ steel in hydrochloric acid. Ind Eng Chem Res 52:14019-14029

40. Yadav M, Bahera D, Kumar S, Sinha RR (2014) Ind J Chem Technol 21:262-272

41. Mistry BM, Patels S, Jauhari SS (2012) Experimental and quantum chemical studies on corrosion inhibition performance of quinoline derivatives for MS in $1 \mathrm{~N} \mathrm{HCl}$. Bull Mater Sci 35:459-469

42. Abdallah M, El-Defrawy AM, Zaafarany IA, Sobhi M, Elwahy AHM, Shaaban MR (2014) Inhibition effects and theoretical studies of synthesized novel bisaminothiazole derivatives as corrosion inhibitors for carbon steel in sulphuric acid. Int J Electrochem Sci 9:2186-2207

43. Gece $\mathrm{G}$ (2008) The use of quantum chemical methods in corrosion inhibitor studies. Corros Sci 50:2981-2992

44. Bedair MA (2016) The effect of structure parameters on the corrosion inhibition effect of some heterocyclic nitrogen organic compounds. J Mol Liq 219:128-141

45. Khaled KF (2008) Molecular simulation, quantum chemical calculations and electrochemical studies for inhibition of mild steel by triazoles. J Electrochim Acta 53:3484-3492

46. Zhang DQ, Pan QY, Gao LQ, Zhou GD (2006) Comparative study of bis-piperidiniummethyl-urea and mono-piperidiniummethylurea as volatile corrosion inhibitors for mild steel. Corros Sci 48:1437-1448

47. Tang YM, Yang WZ, Yin XS, Liu Y, Wan R, Wang JT (2009) Phenylsubstituted amino thiadiazoles as corrosion inhibitors for copper in $0.5 \mathrm{M} \mathrm{H}_{2} \mathrm{SO}_{4}$. Mater Chem Phys 116:479-483

48. Kabanda MM, Murulana LC, Ozcan M, Karadag F, Dehri I, Obot IO, Ebenso EE (2012) Quantum chemical studies on the corrosion inhibition of mild steel by some triazoles and benzimidazole derivatives in acidic medium. Int J Electrochem Sci 7:5035-5056

49. Mert BD, Mert ME, Kardas G, Yazici B, Mert BD, Mert ME, Kardas $G$, Yazici $Y$ (2011) Experimental and theoretical investigation of 3-amino-1,2,4-triazole-5-thiol as a corrosion inhibitor for carbon steel in $\mathrm{HCl}$ medium. Corros Sci 53:4265-4272

50. Lukovits I, Kálmán E, Zucchi F (2011) Corrosion inhibitors-correlation between electronic structure and efficiency. Corrosion 57(1):3-8

51. Rodríguez-Valdez LM, Villamisar W, Casales M, González-Rodriguez JG, Martínez-Villafañe A, Martinez L, Glossman-Mitnik D (2006) Computational simulations of the molecular structure and corrosion properties of amidoethyl, aminoethyl and hydroxyethyl imidazolines inhibitors. Corros Sci 48:4053-4064

Publisher's Note Springer Nature remains neutral with regard to jurisdictional claims in published maps and institutional affiliations. 